\title{
Clinical spectrum of neurofibromatosis type 1 among children in a tertiary care center
}

Fahad A. Bashiri, MD, Lama R. AlZamil, MBBs, Rawan A. Aldhuwayhi, MBBs.

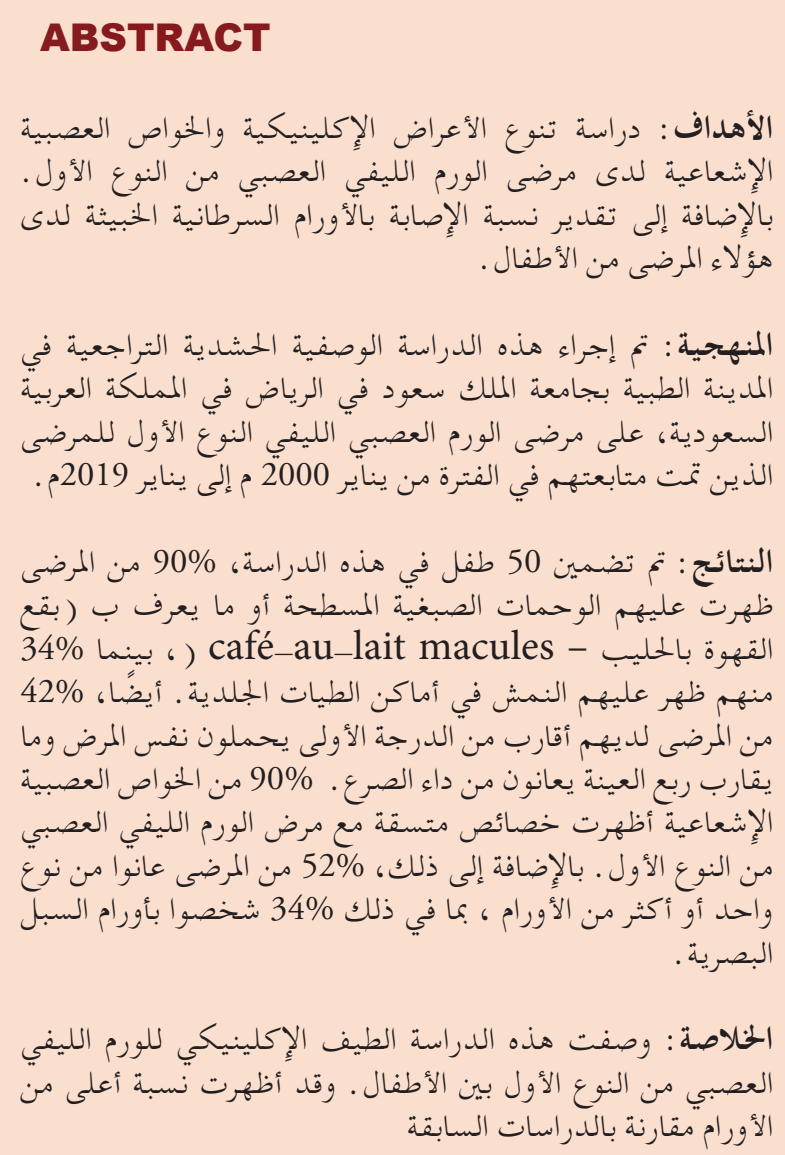

Objectives: To identify the clinical and neuroradiological features of neurofibromatosis type 1 and the risk of malignancy in a pediatric age group.

Methods: This observational retrospective cohort study was conducted at King Saud University Medical City, Riyadh, Kingdom of Saudi Arabia, for the patients with neurofibromatosis type 1 who were seen and had follow up from January 2000 to January 2019.

Results: A total of 50 children were included. Approximately $90 \%$ of patients presented with caféau-lait macules, and $34 \%$ had skin-fold freckling.
Moreover, $42 \%$ of the participants had a first-degree relative with neurofibromatosis type 1 , and about a quarter presented with associated epilepsy. About $90 \%$ of the neuroradiological features were consistent with those of neurofibromatosis type 1 . About $52 \%$ of the patients had one or multiple types of tumors, and $34 \%$ presented with optic pathway glioma.

Conclusion: This study described clinical spectrum of neurofibromatosis type 1 among children. It showed also a higher percentage of tumors than previous studies.

Neurosciences 2020; Vol. 25 (5): 375-379 doi: 10.17712/nsj.2020.5.20200081

From the Division of Neurology (Bashiri), Department of Pediatrics, College of Medicine (AlZamil, Aldhuwayhi), King Saud University, Department of Pediatrics (Bashiri), King Saud University Medical City, King Saud University, Riyadh, Kingdom of Saudi Arabia

Received 21st May 2020. Accepted 30th June 2020.

Address correspondence and reprint request to: Dr. Fahad A. Bashiri, Division of Pediatric Neurology, Department of Pediatrics, College of Medicine, King Saud University. Riyadh, Kingdom of Saudi Arabia. E-mail address: fbashiri@ksu.edu.sa

ORCID ID: https://orcid.org/ 0000-0003-1436-6727

$\mathrm{N}$ eurofibromatosis type 1 (NF1) is an autosomal dominant neurocutaneous disorder, that affects 1 in 3500 people worldwide. ${ }^{1}$ The NF1 is a complex disorder involving multiple body systems, such as the integumentary, visual, skeletal, and central nervous system (CNS); hence, it has different clinical manifestations. This condition is mainly characterized by cutaneous pigmented spots referred to as cafe-au-lait macules. ${ }^{2}$ The diagnosis of NF1 is mainly based on the criteria established by the National Institutes of Health (NIH) in $1988 .{ }^{3}$ Based on these criteria, patients are diagnosed with NF1 if they meet $\geq 2$ of the following criteria: 6 or more cafe-au-lait macules with a diameter measuring $>5 \mathrm{~mm}$ in prepubertal individuals and $>15$ 
mm in postpubertal individuals, 2 or more neurofibromas of any type or one plexiform neurofibroma, axillary or inguinal freckling (Crowe's sign), optic pathway glioma (OPG), 2 or more Lisch nodules, dysplasia of the sphenoid wing or thinning of the long bone cortex $(-/+$ pseudarthrosis), and a first-degree relative with NF1 fulfilling the above mentioned criteria. The diagnostic criteria were revised in 1997 and were continuously used without modifications. ${ }^{4}$ Moreover, patients with NF1 have a higher risk of malignancies than individuals in the general population, with an estimated prevalence of $5 \%$, and these malignancies are usually detected during childhood. ${ }^{1}$

There are no available data on the radiologic features and the signs and symptoms at the time of clinical presentation, which are essential for the clinical knowledge of physicians in identifying patients with such condition. In addition, there is a lack of information about clinical outcomes, including the risk of malignancy, among patients with NF1. Therefore, the current study aimed to evaluate the different clinical manifestations and the radiological features of NF1 among pediatric patients. Moreover, the outcomes, which are essential for urgent interventions that can improve life expectancy, were assessed.

Methods. Study setting. This was an observational retrospective cohort study. The data were extracted from the electronic medical records and the paper records at King Saud University Medical City, Riyadh, Saudi Arabia. The files of the patients were reviewed from January 2000 to January 2019. The study protocol was approved by the institutional review board of the College of Medicine, King Saud University (E19-3826). The inclusion criteria of the study were as follows: aged $\leq 18$ years and individuals who fulfilled $\geq 2$ of the diagnostic criteria for NF1, which include 6 or more cafe-au-lait macules with the greatest diameter measuring $>5 \mathrm{~mm}$ in prepubertal individuals and $>15 \mathrm{~mm}$ in postpubertal individuals, 2 or more neurofibromas of any type or one plexiform neurofibroma, axillary or inguinal freckling, OPG, 2 or more Lisch nodules, dysplasia of the sphenoid wing or thinning of the long bone cortex (-I+ pseudarthrosis), and a first-degree relative with NF1. The primary outcome measures were the different

Disclosure. Authors have no conflict of interests, and the work was not supported or funded by any drug company. clinical manifestations and radiological features of NF1 and the percentage risk of malignancy.

The data collection form comprised demographic data, clinical examination findings, including skin assessment results, head circumference, and blood pressure, diagnostic criteria of NF1, other associated signs and symptoms of NF1, radiological features, and types of tumors identified. The anonymized data in this study were collected from the medical records; therefore, the need for informed patient consent was waived.

Statistical analysis. The mean and standard deviation were used to describe the continuous variables, and the frequencies and percentages were used to describe the categorical variables. There were patients who presented with one or multiple symptoms. Thus, a multiple response dichotomy analysis was performed to describe the prevalence of the signs and symptoms as well as the diagnostic criteria and other (tick-all-that applies) measured characteristics and to identify the applicable diagnostic criteria for each patient. The case summary procedure in the analytical program was used to generate a case summary table showing the detailed information associated with the disease and its outcomes

Results. Demographic characteristics of the participants. A total of 50 patients met the inclusion criteria of the study. Among them, 26 (52\%) were male and 24 (48\%) were female; the mean age was 11 years-old (range: 1-18). The mean age at presentation to the diagnosis of NF1 was 4.5 years. All 50 patients fulfilled 2 or more of the NIH criteria for the diagnosis of NF1, with a mean of 3 diagnostic criteria per patient. The multiple response dichotomy analysis results for the NIH diagnostic criteria observed in our cohort are shown in Table 1. Approximately $90 \%$ of the patients presented with café-au-lait macules, and $34 \%$ had

Table 1 - Descriptive statistics of the diagnostic criteria for NF1 ( $n=50)$.

\begin{tabular}{lc}
\hline Diagnostic criteria & $\mathbf{n}(\%)$ \\
\hline$\geq 6$ Café-au-lait macules & $45(90)$ \\
Skin-fold freckling & $17(34)$ \\
$\geq 2$ Neurofibroma & $6(12)$ \\
$\geq 1$ Plexiform neurofibroma & $12(24)$ \\
$\geq 2$ Iris Lisch nodules & $21(42)$ \\
Optic pathway glioma & $17(34)$ \\
Osseous distinctive lesions & \\
Thinning of the long bone cortex (-/+ pseudarthrosis) & $1(2)$ \\
History of first-degree family with NF1 & $21(42)$ \\
Father & $13(26)$ \\
Mother & $9(18)$ \\
Sibling & $15(30)$ \\
\hline
\end{tabular}


skin-fold freckling, which was commonly observed in the axilla, and OPG. In addition, $42 \%$ had first-degree relatives with $\mathrm{NF1}$, which were mostly siblings and fathers.

As shown in Table 2, signs and symptoms other than those included in the NIH diagnostic criteria were found among patients with NF1. The multiple response dichotomy analysis revealed that $27.3 \%$ of the children presented with congenital or idiopathic scoliosis and $21.2 \%$ with epilepsy. In $29 \%$ of patients with epilepsy, the condition was controlled with a single medication, and $71 \%$ were on multiple antiseizure medications. Neurofibromatosis-Noonan syndrome was observed in 2 patients. Headache was only found in $15 \%$ of the children, and 2 patients were diagnosed with migraine.

Neuroradiological features. Eleven (22\%) patients underwent brain computed tomography (CT) scan. Approximately $63 \%$ of these patients presented with an abnormality on imaging, which is consistent with the diagnosis of NF1. However, only $6 \%$ underwent follow-up CT scan, with a mean number of 1.67 $(\mathrm{SD}=0.6)$. This result showed that these children underwent nearly 2 follow-up CT scans on average. About $36 \%$ of children who underwent initial CT scan had normal findings. Furthermore, approximately $92 \%$

Table 4 - Tumor characteristics of pediatric patients with NF1 (n=30).

\begin{tabular}{|c|c|c|c|}
\hline Type of tumor & $\begin{array}{c}\text { Age } \\
\text { (years) }\end{array}$ & $\begin{array}{c}\text { Age at diagnoses } \\
\text { (years) }\end{array}$ & Locations \\
\hline \multicolumn{4}{|c|}{ Cutaneous neurofibromas ( $n=4)$} \\
\hline $\begin{array}{l}\text { Female } \\
\text { Male } \\
\text { Male } \\
\text { Female }\end{array}$ & $\begin{array}{c}18 \\
3 \\
8 \\
13\end{array}$ & $\begin{array}{c}10 \\
1 \\
1 \\
5\end{array}$ & $\begin{array}{l}\text { Right foot } \\
\text { Trunk, buttock } \\
\text { Right arm } \\
\text { Back }\end{array}$ \\
\hline \multicolumn{4}{|c|}{ Schwannoma $(n=2)$} \\
\hline $\begin{array}{l}\text { Female } \\
\text { Male }\end{array}$ & $\begin{array}{c}14 \\
8\end{array}$ & $\begin{array}{c}10 \\
1\end{array}$ & $\begin{array}{c}\text { Cervical }(\mathrm{C} 1-\mathrm{C} 7) \\
\text { Brain }\end{array}$ \\
\hline \multicolumn{4}{|c|}{ Hamartoma $(n=4)$} \\
\hline $\begin{array}{l}\text { Female } \\
\text { Male } \\
\text { Female } \\
\text { Male }\end{array}$ & $\begin{array}{c}18 \\
13 \\
1 \\
8\end{array}$ & $\begin{array}{c}13 \\
2 \\
3 \\
\text { Not documented }\end{array}$ & $\begin{array}{l}\text { Brain } \\
\text { Brain } \\
\text { Brain } \\
\text { Brain }\end{array}$ \\
\hline \multicolumn{4}{|c|}{ Pilocytic astrocytoma $(n=1)$} \\
\hline Female & 15 & 8 & $\begin{array}{c}\text { Brain } \\
\text { (posterior fossa) }\end{array}$ \\
\hline \multicolumn{4}{|c|}{ Brainstem Glioma $(n=1)$} \\
\hline Female & 13 & 13 & $\begin{array}{c}\text { Brain } \\
\text { (brainstem) }\end{array}$ \\
\hline \multicolumn{4}{|c|}{ Low-grade astrocytoma $(n=1)$} \\
\hline Male & 17 & Not documented & $\begin{array}{c}\text { Brain } \\
\text { (frontal lobe) }\end{array}$ \\
\hline \multicolumn{4}{|c|}{ Optic Pathway Glioma $(n=17)$} \\
\hline Male & 11 & \multicolumn{2}{|c|}{ Bilateral $(\mathrm{n}=9)$} \\
\hline Female & 6 & \multicolumn{2}{|c|}{ Unilateral $(\mathrm{n}=8)$} \\
\hline
\end{tabular}

underwent brain magnetic resonance imaging (MRI) as part of their evaluation. About $69 \%$ of children who underwent brain MRI presented with abnormalities consistent with NF1, and 30\% had normal imaging findings. In addition, hyperintensities on T2-weighted images were observed in $65 \%$ of the patients. Approximately, $80 \%$ of the children underwent follow-up MRI, with a mean number of 2.16 per child $(\mathrm{SD}=2.21)$. The neuroradiological features are summarized in Table 3.

Medical imaging identified various types of tumors, and the analysis showed that $30(60 \%)$ children presented with one or multiple types of tumor. The analysis of the tumor subtypes showed that $56.5 \%$ of the patients had OPG and 52\% had bilateral OPG. Moreover, 21\% of the patients presented with other nonmalignant tumors, including brain hamartomas, which were observed in $13.3 \%$ of the patients. In addition, only $10 \%$ of the

Table 2 - Associated signs and symptoms of NF1 ( $\mathrm{n}=33)$.

\begin{tabular}{lc}
\hline Signs/symptoms & $\mathbf{n}(\%)$ \\
\hline Scoliosis & $9(27.3)$ \\
Epilepsy & $7(21.2)$ \\
Headache & $5(15.2)$ \\
Visual impairment & $5(15.2)$ \\
Intellectual disability & $6(18.1)$ \\
Macrocephaly & $3(9.1)$ \\
Cardiac disease & $2(6.1)$ \\
Central nervous system malformations & $2(6.1)$ \\
Leg length discrepancy & $2(6.1)$ \\
Neurofibromatosis-Noonan syndrome & $2(6.1)$ \\
Learning disabilities & $2(6.1)$ \\
Pseudarthrosis & $1(3)$ \\
Hypertension & $1(3)$ \\
Precocious puberty & $1(3)$ \\
Short stature & $6(18.1)$ \\
\hline
\end{tabular}

Table 3 - Neuroradiological features.

\begin{tabular}{lc}
\hline Radiological testing & $\mathbf{n}(\%)$ \\
\hline Brain CT scan & $11(22)$ \\
Brain MRI & $46(92)$ \\
Hyperintensities on T2WI* & $30(60)$ \\
Tumor types identified, $\mathrm{n}=30$ & $\mathrm{n}(\%)$ \\
Non-neoplastic tumors & $4(13.3)$ \\
Neoplastic tumors & \\
Benign & \\
$\quad$ Hamartoma & $4(13.3)$ \\
Schwannoma & $2(6.6)$ \\
Malignant & $17(56.6)$ \\
Optic pathway glioma & $3(10)$ \\
Intracranial Tumors (Astrocytoma and glioma) & \\
\hline \multicolumn{2}{c}{ *T2WI - T2-weighted image. } \\
\hline
\end{tabular}


patients had malignant cranial tumors. The overall risk of cancer in NF1 patients was approximately $60 \%$. The details of these tumors are presented in Table 4. Finally, only $14 \%$ of the children required surgical intervention for the management of their tumors.

Discussion. This study evaluated the different clinical manifestations and neuroradiological features of NF1 among pediatric patients. All patients in this study met the diagnostic criteria for NF1, with a mean of three criteria per patient, and the mean age at presentation was 4 years. The most prominent of the cardinal criteria for NF1 is the presence of café-au-lait macules, ${ }^{2}$ which was the most prevalent finding in our study, accounting for $90 \%$ of the cases. This result is similar to that of a previous study. ${ }^{5,6}$ Lisch nodules are highly indicative of the disorder. ${ }^{7}$ Approximately 42\% of our patients presented with Lisch nodules, which is similar to that of a previous study. ${ }^{5}$ Similar to the study of Ste-Justine, approximately 3\% of patients presented with hypertension. ${ }^{5}$ Moreover, $27.3 \%$ had scoliosis, and this rate was significantly higher than that of previous studies, with a prevalence rate of $3 \%$ and $11 \% ., 8$ Furthermore, $21.2 \%$ of patients presented with epilepsy, and this rate is three times higher than that previously reported. ${ }^{5}$ Two patients had neurofibromatosis-Noonan syndrome, and its association with the condition has been previously described. ${ }^{9,10}$

The clinical significance of NF1 is that different benign and malignant tumors can develop; therefore, this condition must be diagnosed early in childhood to identify the tumors and improve the outcomes. Most tumors in NF 1 arise from the nervous system. However, NF1 was found to have an increased relative risk for tumors outside the nervous system. ${ }^{11}$ Neurofibroma are considered a hallmark of NF1, and they are benign nerve sheath tumor arising from non-myelinating Schwann cells. They usually present as cutaneous or subcutaneous nodules of varying sizes which can develop anywhere in the body. They are rarely observed in children and usually develop at puberty and are more likely to accumulate with age. ${ }^{12}$ Cutaneous neurofibromas are not at risk of malignant transformation unlike plexiform neurofibromas. However, due to disfigurement and minor discomfort, patients often request to have these tumors resected. By contrast, plexiform neurofibromas involve multiple nerve fascicles, which are usually congenital. They can undergo malignant transformation and develop to malignant peripheral nerve sheath tumors (MPNSTs), with a lifetime risk of $8 \%-13 \%$ in NF1 patients. However, its incidence is rare in the general population. ${ }^{13,14}$ Therefore, plexiform neurofibromas are considered pathognomonic for NF1. In addition, the malignant transformation of plexiform neurofibromas is not common during childhood; however, it can occur in adolescents. ${ }^{15}$ Approximately $24 \%$ of the patients in this cohort presented with at least one plexiform neurofibroma; this finding is similar to that of previous studies. ${ }^{10,16}$ However, the incidence of neurofibromas was significantly lower in our study than in other studies. This result is probably attributed to the fact that our cohort was younger. Hence, none of the patients presented with MPNSTs.

Furthermore, theincidence of gliomasishigher among patients with NF1, and these tumors predominately comprise low-grade pilocytic astrocytomas, which can develop in any part of the brain and spinal cord. However, they commonly involve the optic pathways, brainstem, and cerebellum. ${ }^{17,11}$ The OPG is the most common type of brain tumor associated with NF1; it is usually observed in children aged $<7$ years, with an estimated prevalence rate of $15 \%-20 \% .^{18,19}$ Despite this finding, OPG in childhood is usually indolent and rarely symptomatic and is often detected via routine screening. However, some patients can develop loss of vision, severe proptosis, hydrocephalus, and precocious puberty. ${ }^{18}$ The prevalence of OPG in our study was significantly higher than that in previous studies. A previous study by Boulanger and Larbrisseau et al. compared five different cohorts with NF1 (including that in their study) and reported that the prevalence rate of OPG ranged from $4 \%$ to $19 \%$.

However, compared to our study, OPG had a significantly higher prevalence rate at $56.6 \%$ in a previous study. ${ }^{5}$ Moreover, other intracranial gliomas are common in NF1, and most of them are low-grade gliomas. However, high-grade gliomas can be observed as well. ${ }^{1}$ The second most common brain tumors in NF1 are brainstem gliomas, accounting for $18 \%$ of all NF1CNS tumors. ${ }^{20}$ Unlike the sporadic cases of OPG and brainstem gliomas, these tumors, which are associated with NF1, are more likely to be less aggressive, and several patients are asymptomatic. Therefore, the course is more favorable in this population than in the general population. ${ }^{18,20,21}$ In addition, tumors of the posterior fossa and cerebral hemispheres are not common in NF1 and are more likely to occur at an estimated rate of $1 \%$ and $0.83 \% .{ }^{22}$ In this study, two patients presented with brain astrocytoma, which is located in the frontal lobe and posterior fossa. Other rare malignant tumors associated with NF1 include medulloblastoma and rhabdomyosarcoma. ${ }^{1}$ However, 
these tumors were not observed in the current study. The frequency rate of malignancy in this study was similar to that in previous studies (10\% and 5\%-29\%). ${ }^{23}$

The limitations of the study are the retrospective design, and the relatively small sample size.

In conclusions, this study evaluated the different clinical manifestations and neuroradiological features of NF1 among children. The prevalence of OPG, scoliosis, and epilepsy was higher. Hence, a large multicenter study should be conducted to predict the clinical course of this disorder in the pediatric age group.

Acknowledgment. This research project was supported by a grant from the "Research Center of the Female Scientific and Medical Colleges", Deanship of Scientific Research, King Saud University. And we would like to thank Editage (www.editage.com) for English language editing.

\section{References}

1. Şen H, Aydın B, Varan A, Akyüz C, Kutluk T, Yalçın B. Neurofibromatosis type 1 and malignancy in childhood. Clin Genet 2016; 89: 341-345.

2. DeBella K, Szudek J, Friedman JM. Use of the national institutes of health criteria for diagnosis of neurofibromatosis 1 in children. Pediatrics 2000; 105: 608-614.

3. NIH Consens Statement Online. Neurofibromatosis. p. 1-19.

4. NIH. The National Institutes of Health (NIH) Consensus Development Program. Acupunture. 1997.

5. Boulanger JM, Larbrisseau A. Neurofibromatosis type 1 in a pediatric population: Ste-Justine's experience. Can J Neurol Sci 2005; 32: 225-231.

6. Huson SM, Compston DA, Clark P, Harper PS. A genetic study of von Recklinghausen neurofibromatosis in south east Wales. I. Prevalence, fitness, mutation rate, and effect of parental transmission on severity. J Med Genet 1989; 26: 704-711.

7. Friedman JM. Neurofibromatosis 1: Clinical Manifestations and Diagnostic Criteria. J Child Neurol 2002; 17: 548-554.

8. Cnossen MH, De Goede-Bolder A, Van Den Broek KM, Waasdorp CME, Oranje AP, Stroink H, et al. A prospective 10 year follow up study of patients with neurofibromatosis type 1 . Arch Dis Child 1998; 78: 408-412.

9. Yapijakis C, Pachis N, Natsis S, Voumvourakis C. Is Neurofibromatosis Type 1-Noonan Syndrome a Phenotypic Result of Combined Genetic and Epigenetic Factors? In Vivo (Brooklyn) 2016; 30: 315-320.
10. Rodríguez AD, Moreno GM, Santo-Domingo YM, Martín AH, Roca JES, Rojas MRF, et al. [Phenotypic and genetic features in neurofibromatosis type 1 in children]. An Pediatr (Barc) 2015; 83: 173-182. Spanish

11. Karajannis MA, Ferner RE. Neurofibromatosis-related tumors: Emerging biology and therapies. Curr Opin Pediatr 2015; 27: 26-33.

12. Boyd KP, Korf BR, Theos A. Neurofibromatosis type 1. J Am Acad Dermatol 2009; 61: 1-14.

13. Evans DGR, Huson SM, Birch JM. Malignant peripheral nerve sheath tumours in inherited disease. Clin Sarcoma Res 2012; 2: 17.

14. Uusitalo E, Rantanen M, Roope AK, Pöyhönen M, Leppävirta J, Ylä-Outinen H, Riccardi VM, Eero Pukkala, Janne Pitkäniemi, Sirkku Peltonen, Juha Peltonen. Distinctive Cancer Associations in Patients With Neurofibromatosis Type 1. J Clin Oncol 2016; 34: 1978-1986.

15. Evans DGR, Salvador H, Chang VY, Erez A, Voss SD, Schneider KW, et al. Cancer and central nervous system tumor surveillance in pediatric neurofibromatosis 1. Clin Cancer Res 2017; 23: e46-e53.

16. Cimino PJ, Gutmann DH. Neurofibromatosis type 1. Handb Clin Neurol 2018; 148: 799-811.

17. Ferner RE. Neurofibromatosis 1 and neurofibromatosis 2: a twenty first century perspective. Lancet Neurol [Internet] 2007; 6: 340-351.

18. Melloni G, Eoli M, Cesaretti C, Bianchessi D, Ibba $\mathrm{MC}$, Esposito $\mathrm{S}$, et al. Risk of optic pathway glioma in neurofibromatosis type 1: No evidence of genotype-phenotype correlations in a large independent cohort. Cancers (Basel) 2019; 11.

19. Cynthia J. Campen, David H. Gutmann. Optic Pathway Gliomas in Neurofibromatosis Type 1. J Child Neurol 2018; 33: 73-81.

20. Mahdi J, Shah AC, Sato A, Morris SM, Mckinstry RC, Listernick R, et al. A multi-institutional study of brainstem gliomas in children with neurofibromatosis type 1. Am Acad Neurol 2017; 88: 1584-1589.

21. Peltonen J, Pitkäniemi J, Pöyhönen M, Uusitalo E, Kallionpää RA, Peltonen S, et al. Pediatric malignancies in neurofibromatosis type 1: A population-based cohort study. Int J Cancer 2019; 145: 2926-2932.

22. Pascual-Castroviejo I, Pascual-Pascual SI, Viaño J, Carceller F, Gutierrez-Molina M, Morales C, et al. Posterior fossa tumors in children with neurofibromatosis type 1 (NF1). Childs Nerv Syst 2010; 26: 1599-1603.

23. Zöller ME, Rembeck B, Odén A, Samuelsson M, Angervall L. Malignant and benign tumors in patients with neurofibromatosis type 1 in a defined Swedish population. Cancer 2000; 79: 2125-2131. 